\title{
Uma visão sobre a degradação ambiental causada pelas ocupações irregulares em áreas verdes na cidade de Manaus-AM
}

An insight into the environmental degradation caused by irregular occupations in green areas in the city of Manaus-AM

Una mirada a la degradación ambiental causada por ocupaciones irregulares en áreas verdes de la ciudad de Manaus-AM

Eneida Guerra Silvestrim

ORCID: https://orcid.org/0000-0001-8392-1486 Universidade Federal do Amazonas, Brasil E-mail: egsilvestrim@gmail.com Michael Raphael Soares Vieira ORCID: https://orcid.org/0000-0002-1436-8936 Universidade Federal do Amazonas, Brasil E-mail: michael.soares.vieira@gmail.com

Fernanda Guerra Silvestrim ORCID: https://orcid.org/0000-0002-7571-9795 Faculdade Estácio do Amazonas, Brasil E-mail: ca.ecologica@gmail.com Arlindo Almeida de Lima Filho ORCID: https://orcid.org/0000-0003-0754-0723 Instituto de Pós-graduação e Graduação, Brasil E-mail: arlindo.almeida.filho@gmail.com

Aixa Braga Lopes

ORCID: https://orcid.org/0000-0002-4680-6814 Instituto Nacional de Pesquisas da Amazônia, Brasil E-mail: lopesaixa@gmail.com

\section{Resumo}

A estrutura urbana da capital do Amazonas modificou-se com o processo de urbanização. Em decorrência dessa urbanização acelerada, Manaus, nas últimas três décadas, vem se deparando com um número elevado de ocupações irregulares, as chamadas "invasões". O problema fica evidente quando analisamos o crescimento demográfico populacional. Esse crescimento populacional foi causado pelo gigantesco êxodo rural e pelas migrações regionais, onde enormes massas populacionais foram atraídas principalmente pelas oportunidades de empregos na Zona Franca de Manaus. Este trabalho considerou o ocorrido com duas grandes ocupações irregulares na cidade de Manaus nos últimos anos, a ocupação da "Cidade das Luzes" e do "Monte Horebe" e como as ações tomadas pelas autoridades impactaram nessas ocupações irregulares. O impacto dessas ocupações irregulares,que florescem sem qualquer prévia infraestrutura e sem saneamento básico, tem contribuído para a degradação de áreas verdes importantes para a cidade. A metodologia utilizada foi a análise de dados de georreferenciamento Google Earth Pro e dados do Mapeamento Anual do Uso e Cobertura da Solo no Brasil. Como resultado, a reintegração de posse do Monte Horebe se apresentou como um marco significativo na reintegração de posse de áreas irregulares, pois foi possível, através de acordo para a entrega de vales-aluguel e da vigilância da área, que foi reocupada para um fim social (no caso, uma escola de tempo integral). Já é possível ver, inclusive, por fotos de satélite, que já ocorre uma recuperação da área degradada.

Palavras-chave: Invasões; Impacto; Cidade das Luzes; Monte Horebe.

\begin{abstract}
The urban structure of the capital of Amazonas changed with the urbanization process. As a result of this accelerated urbanization, Manaus, in the last three decades, has been facing a high number of irregular occupations, the so-called "invasions". The problem becomes evident when we look at population demographic growth. This population growth was caused by the gigantic rural exodus and regional migrations, where huge populations were attracted mainly by the job opportunities in the Manaus Free Trade Zone. This paper considered what happened with two large irregular occupations in the city of Manaus in recent years, the occupation of the "City of Lights" and "Monte Horebe" and how the actions taken by the authorities impacted these irregular occupations. The impact of these irregular
\end{abstract}


occupations, which flourish without any prior infrastructure and basic sanitation, has contributed to the degradation of important green areas for the city. The methodology used was the analysis of Google Earth Pro georeferencing data and data from the Annual Land Use and Coverage Mapping in Brazil. As a result, the repossession of Mount Horeb presented itself as a significant milestone in the repossession of irregular areas, as it was made possible through an agreement for the delivery of rental vouchers and the surveillance of the area, which was reoccupied for a purpose. social (in this case, a full-time school). It is already possible to see, even through satellite photos, that the degraded area is already recovering.

Keywords: Invasions; Impact; City of Lights; Mount Horeb.

\section{Resumen}

La estructura urbana de la capital de Amazonas cambió con el proceso de urbanización. Como resultado de esta urbanización acelerada, Manaos, en las últimas tres décadas, ha estado enfrentando un alto número de ocupaciones irregulares, las llamadas "invasiones". El problema se hace evidente cuando observamos el crecimiento demográfico de la población. Este crecimiento poblacional fue causado por el gigantesco éxodo rural y las migraciones regionales, donde grandes masas de población fueron atraídas principalmente por oportunidades laborales en la Zona Franca de Manaus. Este trabajo consideró lo sucedido con dos grandes ocupaciones ilegales en la ciudad de Manaus en los últimos años, la ocupación de la "Ciudad de las Luces" y el "Monte Horebe" y cómo las acciones de las autoridades impactaron estas ocupaciones irregulares. El impacto de estas ocupaciones irregulares, que florecen sin ninguna infraestructura previa y saneamiento básico, ha contribuido a la degradación de importantes áreas verdes para la ciudad. La metodología utilizada fue el análisis de datos de georreferenciación de Google Earth Pro y datos del Mapeo Anual de Uso y Cobertura del Suelo en Brasil. Como resultado, la recuperación del monte Horeb se presentó como un hito significativo en la recuperación de áreas irregulares, ya que fue posible a través de un acuerdo para la entrega de vales de alquiler y la vigilancia de la zona, que fue reocupada con un propósito. social (en este caso, una escuela a tiempo completo). Ya es posible ver, incluso a través de fotos de satélite, que la zona degradada ya se está recuperando.

Palabras clave: Invasiones; Impacto; Ciudad de Luces; Monte Horeb.

\section{Introdução}

Aglomerado Subnormal é um tipo de ocupação realizada de maneira irregular, também conhecido como invasão, baixada, favela, vila, loteamento irregular e comunidade, entre outros, visando a habitação, em terrenos de propriedade alheia, que podem ser em áreas urbanas ou mesmo rurais, privados ou públicos, em que as habitações são construídas em áreas de ocupação restrita e com padrão urbanístico irregular, sem os serviços essenciais de infraestrutura e saneamento básicos (IBGE, 2019).

É importante "garantir o acesso de todos a moradia digna, adequada e a preço acessível; aos serviços básicos e urbanizar os assentamentos precários de acordo com as metas assumidas no Plano Nacional de Habitação, com especial atenção para grupos em situação de vulnerabilidade” (IPEA, 2019, p. 8). Assim, as moradias sem o correto abastecimento de água, esgotamento sanitário, coleta de lixo, densidade de moradores por cômodos servindo como dormitório, ônus excessivo de aluguel no orçamento familiar, constituem condição de domicílio subnormal.

A cidade de Manaus é valorizada devido à sua localização no coração da Amazônia, lugar de maior biodiversidade no mundo e do maior banco genético do planeta, fonte primordial para a ciência e a tecnologia (Rodrigues, 2020).

Os Aglomerados Subnormais na cidade de Manaus, iniciaram-se durante a expansão no período da borracha. Segundo o autor (Benchimol, 2009), nesse período houve um impulso no crescimento demográfico da capital amazonense, juntamente ao progresso econômico derivado do comércio da borracha, com a construção de ruas, avenidas e do Teatro Amazonas.

As mudanças trazidas pelo processo de industrialização, afetaram rapidamente a vida cotidiana dos amazonenses. O processo de avanço do desmatamento tem sido a causa mais potente de mudança.

Os seres humanos têm realizado degradações e contribuído para alterar as características de alguns dos principais biomas, incluindo as florestas secundárias, margens de desertos, savanas, pradarias, várzea e matagais mediterrânicos (Simon, 2014). 
Research, Society and Development, v. 10, n. 16, e290101623764, 2021

(CC BY 4.0) | ISSN 2525-3409 | DOI: http://dx.doi.org/10.33448/rsd-v10i16.23764

A estrutura da capital do Amazonas modificou-se com o processo de urbanização. Em decorrência dessa urbanização acelerada, Manaus, nas últimas três décadas, vem se deparando com um número elevado de Aglomerados Subnormais, as chamadas "invasões". O problema fica evidente quando analisamos o crescimento demográfico populacional. Esse crescimento populacional foi causado pelo gigantesco êxodo rural e pelas migrações regionais, onde enormes massas populacionais foram atraídas pelas promessas da Zona Franca de Manaus (de Souza et al., 2015).

Consideremos também os fluxos migratórios para o Brasil, de pessoas oriundas de países como o Haiti, devido às catástrofes naturais como o terremoto de 2010 e o furacão Matthew de 2016 e, por último, oriundas da Venezuela, originado do incremento da forte crise política e de abastecimento. Esses fluxos migratórios inundaram a cidade de Manaus de refugiados. E, embora o exponencial aumento do fluxo migratório de venezuelanos até os dias de hoje para o território brasileiro, possua flagrante conteúdo geopolítico, acaba por refletir no aumento da ocupação desordenada dentro das áreas invadidas (Nogara \& Wobeto, 2019).

A imigração desordenada para a cidade de Manaus, juntamente com a observação da Portaria Interministerial $\mathrm{n}^{\circ}$ 09/2018, que dispõe sobre a concessão de autorização de residência ao imigrante que esteja em território brasileiro e seja nacional de país fronteiriço e a Lei de Migração que permite que, o imigrante, o residente fronteiriço e o visitante possam pedir uma autorização de residência no território nacional, contribuíram para que muitos desses imigrantes, em situação precária, se juntassem aos aglomerados subnormais (Oliveira, 2020).

As áreas degradadas em geral, precisam ser recuperadas, principalmente as áreas verdes, onde as principais atividades degradadoras são: agricultura, mineração, desertificação e urbanização descontrolada. Porém, existem vários modelos e técnicas para a recuperação de uma área degradada, cuja escolha depende da situação de degradação da área e das condições de regeneração do ecossistema afetado (Aquino, 2011).

O objetivo central da recuperação de uma área que foi degradada por ações antrópicas é o restabelecimento de florestas que sejam capazes de se autoperpetuar, ou seja, florestas biologicamente viáveis e que não dependam de intervenções humanas constantes. De forma geral, as iniciativas de restauração ambiental visam o cumprimento da legislação, ao restabelecimento de serviços ecossistêmicos e a proteção de espécies nativas (Brancalion et al., 2010).

Anualmente, novas invasões são feitas na capital amazonense. Diante do exposto, essa análise visou destacar os principais impactos que podem ser ocorrentes nas áreas degradadas dos Aglomerados Subnormais Cidade das Luzes e Monte Horebe, localizadas em Manaus - AM.

\section{Metodologia}

O local escolhido para pesquisa foi a cidade de Manaus, conforme figura 1, com o objetivo de analisar o Aglomerado Subnormal chamado "Cidade das Luzes", situado no bairro Tarumã, na zona oeste de Manaus/AM, que possui aproximadamente 820.883,22 m³ , cujas respectivas coordenadas são latitude: 2 $2^{\circ} 59^{\prime} 29$ 40"' S, longitude 60 4'4 94" W e o Aglomerado Subnormal "Monte Horebe" situado na zona norte de Manaus, cujas respectivas coordenadas são latitude: $2^{\circ}$ $57^{\prime} 48$. 2"' S, longitude $59^{\circ} 58^{\prime} 47$. 3"' W. 
Research, Society and Development, v. 10, n. 16, e290101623764, 2021

(CC BY 4.0) | ISSN 2525-3409 | DOI: http://dx.doi.org/10.33448/rsd-v10i16.23764

Figura 1 - Localização da área de estudo.

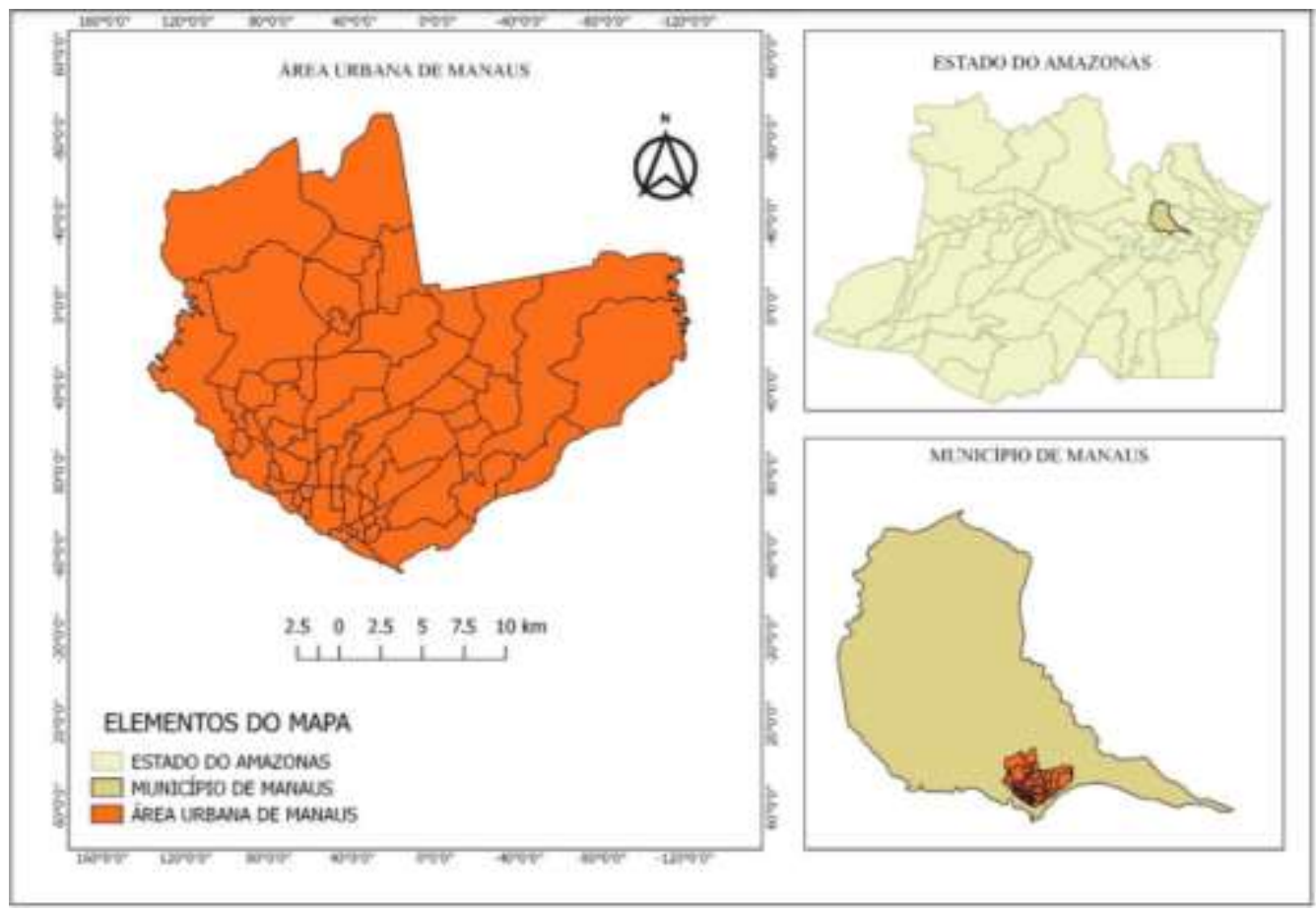

Fonte: De Souza \& Da Cunha Albuquerque (2020).

O método utilizado foi o método qualiquantitativo. Segundo Pereira et al. (2018) qualitativo, porque a interpretação e opiniões do pesquisador são importantes sobre o fenômeno em estudo e os dados coletados são em sua maioria descritivos e quantitativo, porque a coleta de dados quantitativos ou numéricos é realizada por meio do uso de medições de grandezas e obtém-se por meio da metrologia e números com suas respectivas unidades.

É também descritivo, pois este método parte do princípio de que o estudo de caso em profundidade pode ser considerado representativo de muitos outros, ou mesmo de todos os casos semelhantes (Gil, 2008). A contextualização é de cunho exploratório de caráter qualitativo pois visa empregar, registar fatos que foram observados sem deixar de citar as variáveis.

No primeiro momento foi feita a leitura de referências bibliográficas, para verificar o histórico de impactos ambientais em áreas invadidas. Todo o processamento de dados foi realizado por meio da ferramenta de georreferenciamento Google Earth Pro para calcular e delimitar a área que foi desmatada. Esse software permite a sobreposição de planos de informações vetoriais e matriciais, desenvolvendo um mapeamento temático e foi utilizado para a coleta de dados como séries históricas de imagem de 2010 a 2021, catalogação da área e dados geográficos e relatórios dos órgãos fiscalizadores, como a Secretaria de Estado do Meio Ambiente - SEMA/AM e artigos de jornais catalogados. Serão analisados dados secundários da organização Projeto de Mapeamento Anual do Uso e Cobertura da Terra no Brasil (MapBiomas,2021), com os dados de cobertura e transições dos municípios, analisando dados de área (ha) e por tipo de cobertura e uso do solo por município entre os anos de 1985 a 2020.

\section{Resultados e Discussão}

No período de 1985 a 2020, as áreas urbanizadas no país passaram de 2,1 milhões de hectares para 4,1 milhões de hectares. A expansão urbana no Brasil tem crescido a uma taxa anual de 1,97\%, superior à taxa de crescimento da população, de $1,45 \%$. 
Figura 2 - Expansão da Informalidade Urbana.

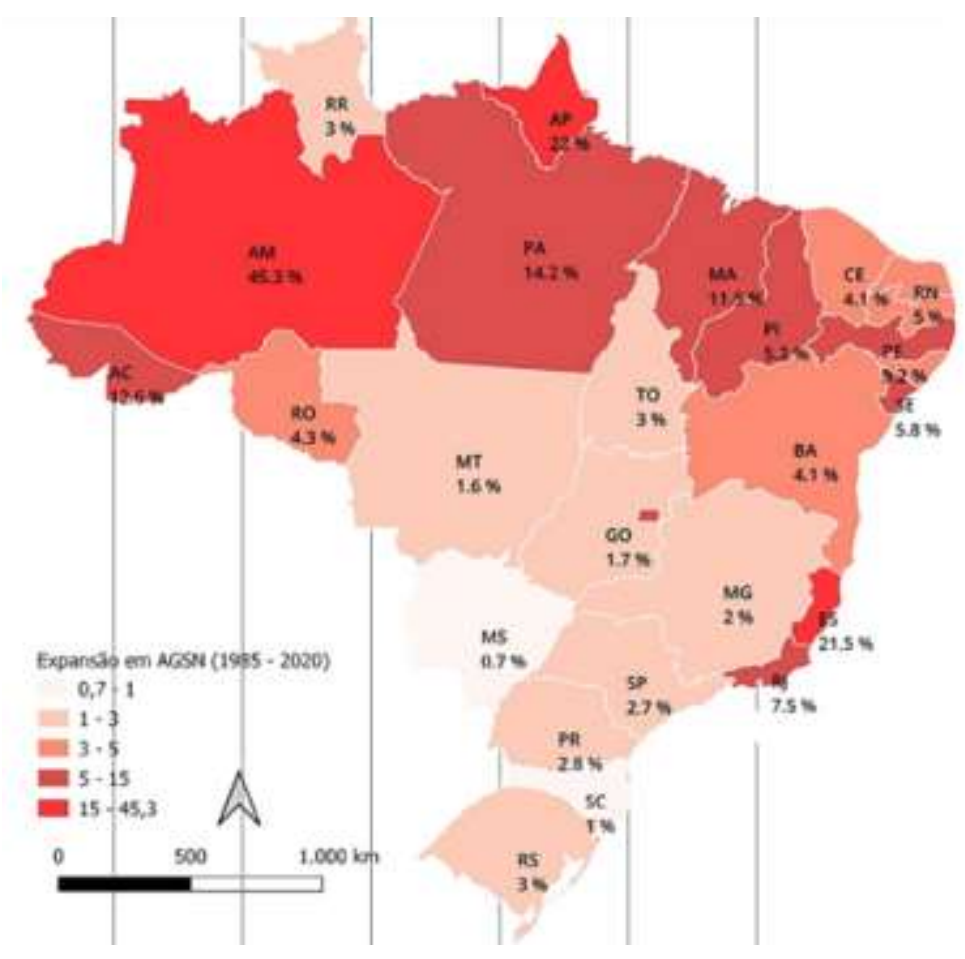

Fonte: MapBiomas(2021).

Por todo o Brasil, os aglomerados subnormais cresceram exponencialmente entre 1985 e 2020 e cerca de 4,66\% do crescimento dessas áreas urbanizadas derivam da informalidade (invasões). São áreas mais sensíveis às políticas econômicas e sociais, se desenvolvendo mais em períodos de retração do PIB. A Amazônia tem o maior percentual de crescimento de aglomerados subnormais do Brasil. Um total de 18,2\% do crescimento urbano em áreas informais.

Nos dados analisados foi apresentado que nas duas grandes capitais da região norte, a informalidade tem sido a regra nos últimos 36 anos, já que, nos dois casos, os percentuais se mantêm acima dos 50\%. Belém tem 51\% de sua área urbanizada ocupada pela informalidade, enquanto em Manaus esse percentual é de 48\%. No Amazonas, essa informalidade corresponde a 45\% do total da área urbanizada; no Amapá, 22\%; no Pará, 14\%; e no Acre, 12,6\% (Figura 2). Nessa análise de área total urbanizada ocupada informalmente, Manaus, Belém e Salvador se destacam.

A Amazônia é conhecida por sua grande disponibilidade hídrica, o que se mede por uma densa rede de drenagem que corta uma vasta região geográfica com rios, lagos e igarapés com grande variabilidade tanto na extensão, quanto na largura dos rios, bem como no volume de água por eles transportado. A hidrografia da região amazônica, próxima da região invadida, é caracterizada por ser um braço do efluente Rio Negro de característica delta, segundo o (de Macena \& Costa, 2012).

Antes de ocorrerem as ocupações irregulares, a cobertura vegetal se apresentava predominantemente como floresta tropical densa, característica da floresta Amazônica. A região da zona oeste de Manaus tem as formações de floresta tropical aberta, floresta aluvial periodicamente inundada (igapó), campinarana, área de tensão ecológicas, como formações edáficas e áreas antrópicas (Magalhães et.al., 2011).

Ainda de acordo com (Oliveira, et al., 2008), a área desmatada eleva as características da intensidade da radiação solar incidente na superfície, bem como o fluxo de calor ganho ou perdido para a atmosfera (Figura 6). Já do ponto de vista de (AMAZONAS, 2009), os conteúdos de umidade do solo e precipitação, também são fatores que influenciam principalmente na umidade relativa do ar, por meio da evapotranspiração, o que é diretamente refletido no ciclo das chuvas. 
Research, Society and Development, v. 10, n. 16, e290101623764, 2021

(CC BY 4.0) | ISSN 2525-3409 | DOI: http://dx.doi.org/10.33448/rsd-v10i16.23764

$\mathrm{Na}$ área ocupada irregularmente, não existe coleta de resíduos sólidos, acarretando a queima dos resíduos acumulados no local e, como um dos impactos, Manaus sofre com a fumaça que circula por toda cidade. Segundo Farias (2015), a fumaça na atmosfera de Manaus é proveniente das queimadas ocorrentes próximas a capital.

A fauna também é seriamente afetada, os impactos do desmatamento podem afetar o bem-estar e o comportamento dos animais silvestres e, em casos extremos, podem até extinguir alguma espécie que esteja ameaçada, como os principais animais existentes da região amazônica, segundo (da Silva \& Andrade, 2017).

Este trabalho destaca os aglomerados subnormais recentes dos bairros "Cidade das Luzes" e "Monte Horebe" como exemplo de áreas verdes que foram degradadas na cidade de Manaus nos últimos anos. Estes locais, foram selecionados para pesquisa pois, embora hoje Manaus tenha vários bairros consolidados, antes dessa consolidação, muitos desses bairros tiveram origem em um aglomerado subnormal e acabaram se transformando em bairros. Os principais impactos observados in loco, são ressaltados na forma de desmatamento e compactação do solo, entre outros (Oliveira et al., 2021). Quase sempre, em áreas de invasões antrópicas, o índice de desmatamento é alto, pois ocorre a construção dos barracos e a retirada da vegetação e posterior queima do solo, para limpar o terreno, impacta diretamente na qualidade deste solo, além de outros impactos como a perda da cobertura vegetal e a compactação do solo (Alves et al., 2020).

Através de análises feitas através do software (Google Earth Pro, 2021), foi possível identificar quando foi o período em que se iniciou a invasão da Cidade das Luzes. De acordo com o histórico de dados de imagens obtidas pelo software nos períodos de 2010 a 2021 a área, de caráter privado, fica nas proximidades do Parque das Tribos, onde residem sociedades indígenas do Amazonas. Segundo as análises de 2010 até 2021, em 2010 podia-se ver a vegetação e que estava praticamente intacto o local, sem grande significância de desmatamento e ocupações (Figura 3-A), já em 2015 observa-se desmatamento causado pelo aglomerado subnormal (Figura 3-B), onde observa-se, desde o início da invasão, o crescimento do desmatamento na região. A área desmatada no local possui o território com $820.883,22 \mathrm{~m}^{3}$ invadido. O desmatamento acarreta um sério desequilíbrio ecológico, principalmente em áreas invadidas. O desmatamento mais evidente até 2021(Figura 3- C, D).

Figura 3 - Série Histórica em georreferenciamento do aglomerado subnormal da Cidade das Luzes em Manaus-AM.

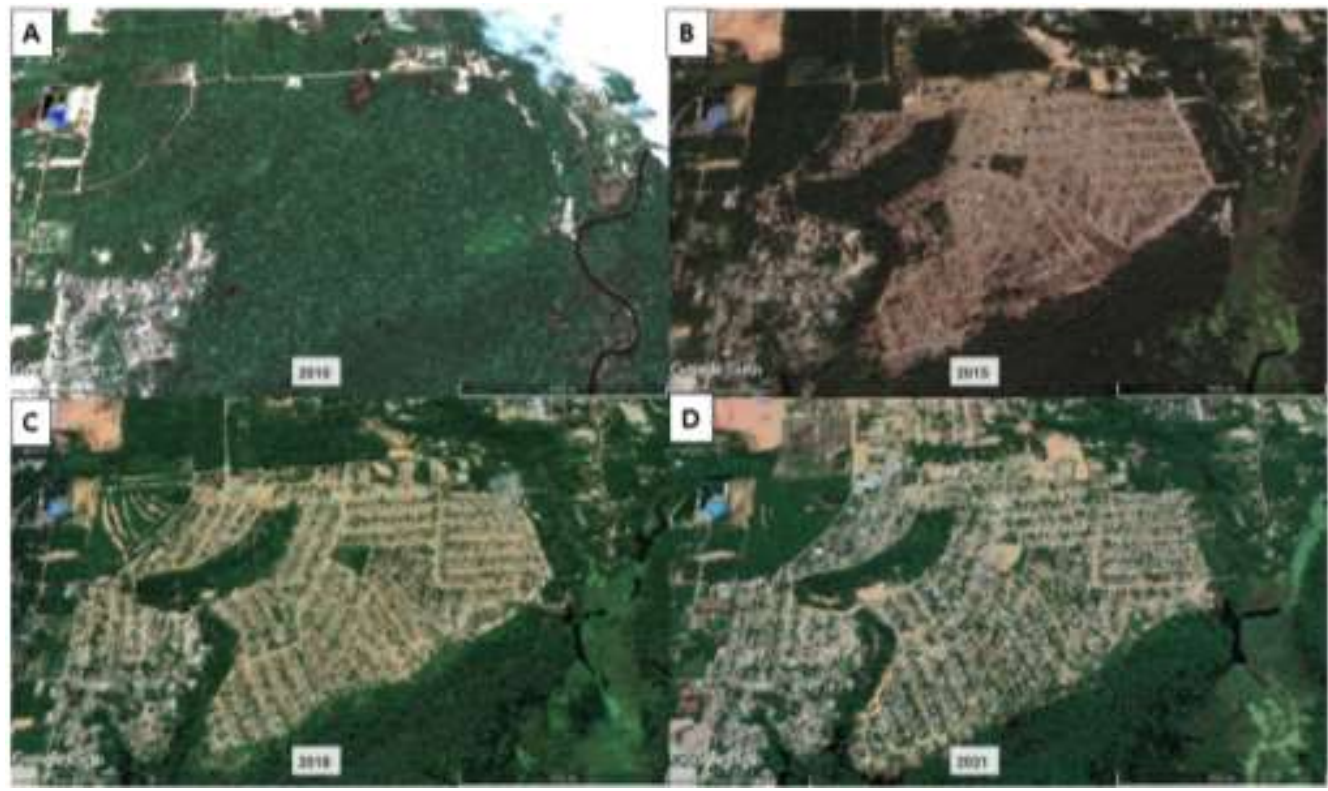

Fonte: Acervo dos autores Google Earth-Pro (2021).

A causa da degradação do local, de acordo com (Maciel, 2016), está relacionada ao aumento populacional 
descontrolado de Manaus. Segundo as análises das alterações e danos ambientais causados pela construção dos barracos na área invadida, foram principalmente observadas as mudanças drásticas na cobertura vegetal ocasionada pelo desmatamento.

Os índices de doenças infectocontagiosas aumentam em áreas ambientalmente degradadas, como por exemplo o processo de ocupação da localidade São Pedro, onde houve a incidência epidêmica de casos de dengue e malária em decorrência do agressivo processo de desmatamento dos espaços verdes (Aquino, 2017).

O impacto dos aglomerados subnormais está nas áreas degradadas, ocorrente devido às ações antrópicas, causando alterações das propriedades físicas, químicas e biológicas da área invadida e essas alterações tendem a comprometer a estrutura do local e o funcionamento do ecossistema natural de forma temporária ou definitiva, tornando aquele ambiente perturbado.

As moradias construídas nos aglomerados subnormais, mostram-se precárias, em madeira e compensado e sem infraestrutura e saneamento básico aparente. Os barracos construídos sem nenhuma salubridade, os dejetos sendo diretamente despejados em buracos com cerca de um metro de altura do nível do chão, não existindo saneamento básico. O principal impacto dos resíduos excretados pelos humanos diretamente no solo, é a contaminação do solo e lençóis freáticos (Figura 4-A, B).

Figura 4 - Aglomerado Subnormal da Cidade das Luzes em Manaus-AM.

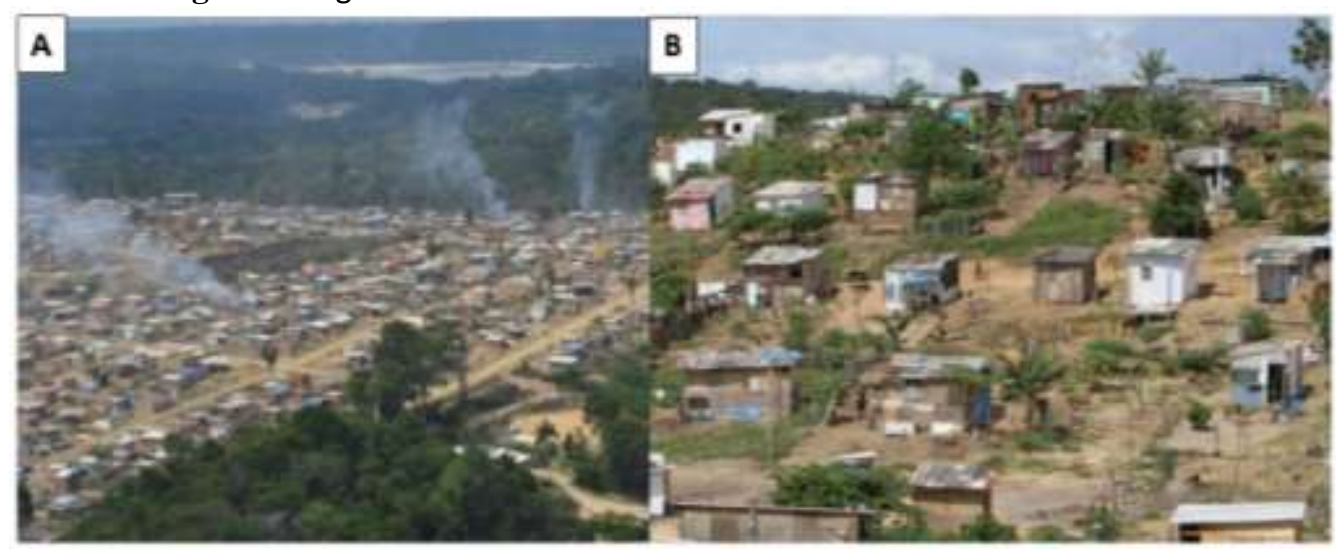

Fonte: Abadias et al. (2018).

O governo do Amazonas, ao adotar medidas para retirar os indivíduos que invadiram o local, propiciou alojamento em residências com saneamento básico e segurança gerando para aquela população, mais qualidade de vida. No entanto, é difícil agir em períodos eleitorais, quando candidatos à eleição, iludem indivíduos com falsas promessas, principalmente no caso dos invasores de terras, quando são estimulados a continuarem na área invadida em troca de votos.

Citando outro exemplo, segundo (Batista, 2016), na década de 1980, o loteamento do Bairro São José zona leste de Manaus, foi o marco inicial da expansão urbana nessa zona da cidade, caracterizado por invasões, loteamentos e conjuntos habitacionais de baixa renda. Esses dados são bem semelhantes aos dados presentes nas invasões da Cidade das Luzes e do Monte Horebe.

Os dados dos efeitos causados pelos danos ambientais são elementos referentes ao ambiente físico e biológico da área e foi observado que o solo na região se enquadrava como solo argiloso. Segundo (Derisio, 2016), no Amazonas, os solos argissolos, em sua maioria, oferecem reação moderadamente ácida, são suscetíveis aos processos de erosão hídrica, principalmente quando ocorre relevo ondulado. A caracterização desse tipo de solo, compreende os solos minerais não hidro mórficos.

Segundo (batista, 2016), entende-se por erosão o processo de "desagregação e remoção de partículas do solo ou de fragmentos e partículas de rochas, pela ação combinada da gravidade com a água, vento, gelo ou organismos". Na cidade de 
Research, Society and Development, v. 10, n. 16, e290101623764, 2021

(CC BY 4.0) | ISSN 2525-3409 | DOI: http://dx.doi.org/10.33448/rsd-v10i16.23764

Manaus observa-se a destruição de ruas e estradas asfaltadas. Isso normalmente está relacionado aos solos argissolos e, na invasão Cidade das Luzes não existe cobertura asfáltica e não há cobertura vegetal. Portando, as chances de erosões de todas as formas são bastante propícias.

A área do aglomerado subnormal Monte Horebe é próxima à Reserva Florestal Adolpho Ducke e, mesmo nas imediações do conjunto habitacional Viver Melhor, o maior conjunto habitacional do País dentro do programa Minha Casa Minha Vida, constituiu-se sem saneamento básico ou água e a energia muito precária (Figura 5).

Figura 5 - Série Histórica em georreferenciamento do aglomerado subnormal Monte Horebe em Manaus-AM.

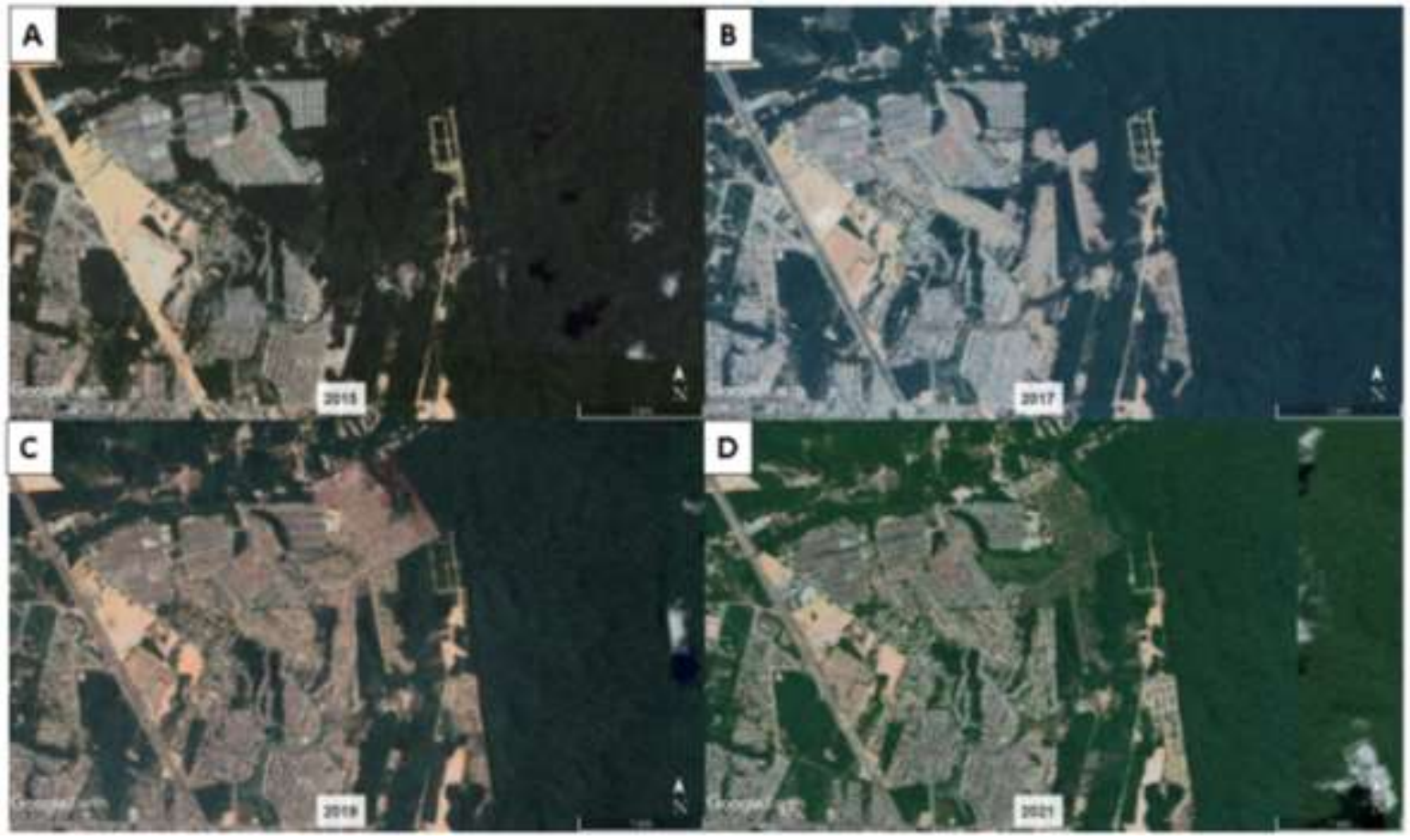

Fonte: Acervo dos autores Google Earth-Pro (2021).

Observa-se a área preservada (Figura 5-A), o início da ocupação e construções de barracos (Figura 5-B) e a área ocupada por barracos, visivelmente desmatada (Figura 5-C).

Então, em março de 2020 foi iniciada, pelo governo do Estado do Amazonas, uma ação de desocupação no Aglomerado Subnormal Monte Horebe, que é considerado um dos maiores aglomerados subnormais da cidade. Foram cadastrados pelo governo, cerca de 2.340 imóveis e foram retiradas por ocasião da reintegração, 2.204 famílias, que aceitaram receber do governo um auxílio-aluguel, como parte do acordo de reintegração de posse.

Essa reintegração de posse e o acordo, ocorreram a partir de mandado judicial expedido no Processo Judicial $\mathrm{n}^{\circ}$ 0621776-31.2014.8.04.0001. Após a desocupação da área, a Secretaria Estadual de Meio Ambiente (Sema), juntamente com a Delegacia Especializada em Crimes contra o Meio Ambiente e o Instituto de Proteção Ambiental do Amazonas, fez levantamentos de dados para analisar o volume e os tipos de danos ambientais na área, que compreende 140 hectares. $\mathrm{O}$ resultado possibilitou ao Governo do Estado a elaboração de um plano para a ocupação da área, uma prioridade, devido à sua localização delicada, a apenas 260 metros em linha reta da Área de Proteção Ambiental (APA) Adolpho Ducke. Observando-se a vegetação voltando à área (Figura 5-D). 
Figura 6 - Aglomerado subnormal Monte Horebe em Manaus-AM.

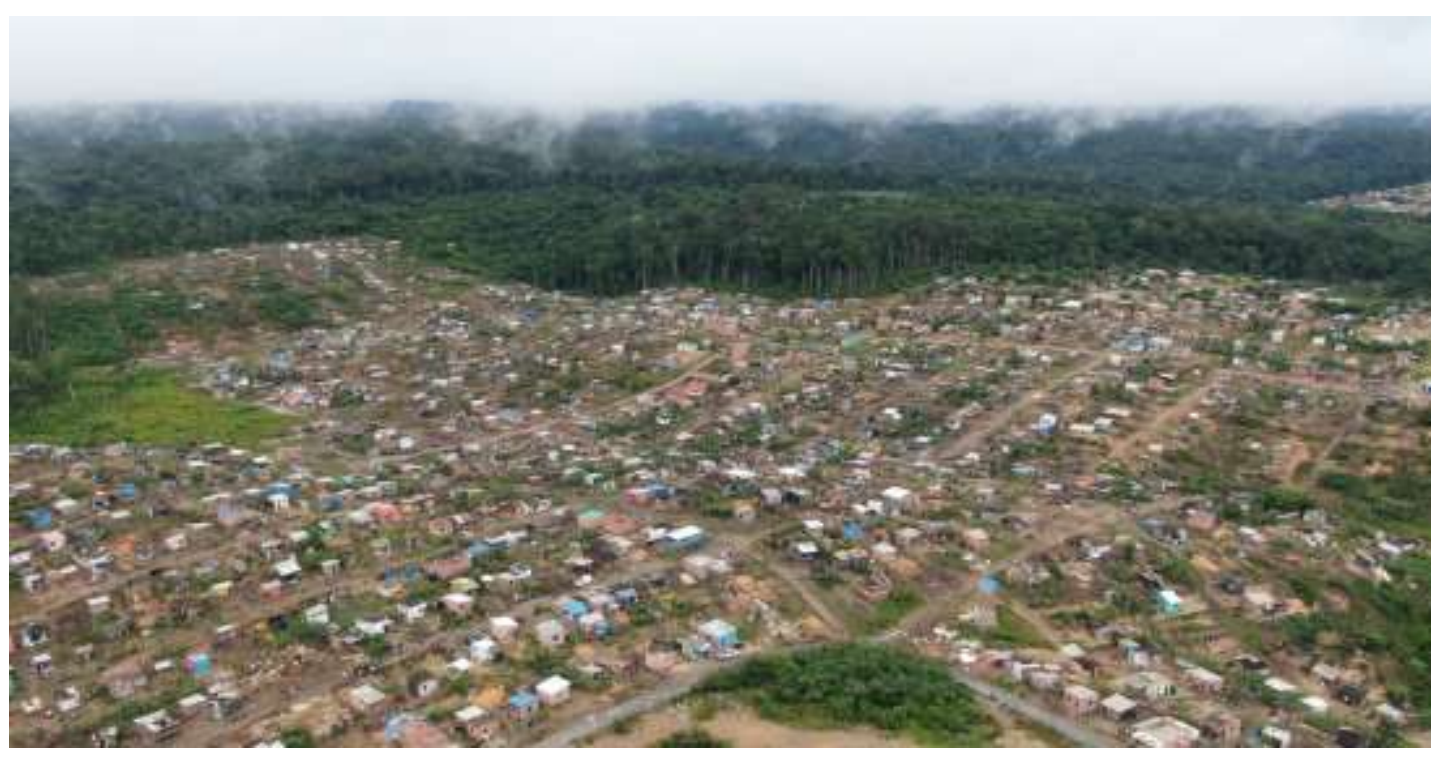

Fonte: Acervo dos autores Google Earth-Pró (2021).

Como é observado na área invadida (Figura 6), o solo ficou com barracos no lugar onde antes existiam as coberturas verdes e, segundo (GIANGIULIO, 2009), no momento em que o solo permaneceu exposto, tornou-se mais vulnerável à erosão.

Dentre os meios para impedir que ocorram erosões, procede-se inserindo espécies gramíneas que não exigem tanto do solo, água e dos nutrientes. E, segundo o (MMA, 2013), a introdução de espécies depende do estado da área alterada, como por exemplo, as espécies Eucalyptus spp, Leucaena leucocephala, Cana-de-açúcar entre outras. De acordo com (Aquino, 2011), outras espécies favoráveis para o tipo de solo da área invadida são espécies Ingá-de-metro (Ingá edulisMart), Goiaba de anta (Belluciagrossularioide), Guaraná (PaulliniacupanaKunth), Cupuaçu (Theobroma grandiflorum) e a Leucena (Leucaena leucocephala) entre outras. As raízes dessas espécies são eficazes na descompactação do solo, pois as micro raízes irão distribuir oxigenação no interior do solo, facilitando assim a infiltração entre outros aspectos.

Os autores (Durigan \& Engel, 2012) citam que, para evitar novas degradações antrópicas, essas medidas podem ser feitas através cercamento da área e emplacamento. No entanto, não se trata exclusivamente da cautela ambiental destas áreas, mas, é especialmente uma dificuldade socioeconômica derivada das questões de moradia do país e atinge abertamente uma parte da sociedade com menos recursos financeiros.

\section{Considerações Finais}

Os Aglomerados Subnormais são uma realidade e as consequências a curto e longo prazo podem ser ainda mais alarmantes do que tem sido observado até então. As implicações em graves impactos no desmatamento, na compactação no solo, na perda da cobertura vegetal, na fauna, no solo, na hidrologia da região e ainda no efeito estufa, pois a retirada da vegetação indiscriminadamente e, muitas vezes, através de queimadas para a colocação de barracos, contribui na elevação da emissão de gases de efeito estufa, que influenciam diretamente em fenômenos climáticos. Isso interfere na imagem da cidade de Manaus, coração da Amazônia, que não consegue cumprir os objetivos de desenvolvimento sustentável da agenda 2030.

Este estudo demonstra ser de vital importância, os investimentos em moradias populares, pois a principal causa do surgimento de aglomerados subnormais é a dificuldade socioeconômica e, as questões de moradia do país atingem abertamente uma parte da sociedade com menos recursos financeiros. São necessários projetos mais eficazes de moradias, para que possam 
dar respaldo aos interesses comunitários, permitindo significativas trocas de reconhecimento e valorização socioambiental, bem como a preservação social, cultural e do meio ambiente (Limeira, 2017).

A causa da degradação do local, de acordo com (Maciel, 2016), está relacionada ao aumento populacional descontrolado de Manaus. Segundo as análises das alterações e danos ambientais causados pela construção dos barracos na área invadida, foram principalmente observadas as mudanças drásticas na cobertura vegetal ocasionada pelo desmatamento.

Por outro lado, é imperativo a vigilância das áreas verdes, principalmente as próximas às áreas de preservação ambiental, para evitar danos ambientais irremediáveis e ainda, que seja observada a necessidade de envolver a população no processo de fiscalização, através da realização de denúncias, sobre os aglomerados subnormais que venham a despontar pela cidade nestas áreas vulneráveis.

A reintegração de posse do Monte Horebe se apresentou como um marco significativo na reintegração de posse de áreas irregulares, pois foi possível, através do acordo para a entrega de vales-aluguel e da vigilância da área, que foi reocupada para um fim social (no caso, uma escola de tempo integral). Já é possível ver, inclusive, por fotos de satélite, que já ocorre uma recuperação da área degradada. Esse resultado, possibilitado pela cooperação entre os órgãos do governo, uma parceria importante para dar continuidade ao controle de ocupação de áreas verdes importantes à região, principalmente nas áreas de proteção ambiental. Serão importante pesquisas constantes na evolução dos aglomerados subnormais da cidade, para que se possa ter sempre um diagnóstico atual e preciso para a tomada de decisões quanto às possíveis soluções para este problema ambiental.

Faz- se necessária a realização de trabalhos futuros tendo em vista a melhoria contínua no processo de fiscalização e monitoramento de áreas de proteção permanente.

\section{Referências}

Abadias, A. M. P., de Lima, A. A., \& Oliveira, I. F. (2018). Environmental impacts Caused by Irregular Occupation around the City of Lights, in the city of Manaus-AM. doi: 10.22161/ijaers.612.6

Amazonas. (2009). Governo do Estado. A floresta amazônica e seu papel nas mudanças climáticas / Secretaria de Estado do Meio Ambiente e Desenvolvimento Sustentável. Manaus: SDS/CECLIMA.

Amazonas. (2021). Governo do Estado. http://www.manaus.am.gov.br/noticia/fauna-silvestre-workshop

Alves, A. C., Freitas, I. S. D., \& Santos, M. Q. D. (2020). Análise multitemporal da expansão urbana da cidade de Manaus, Amazonas, utilizando imagens de satélite.

Aquino, G. (2017). Processo Saúde doença e determinantes socioambientais no território de risco do bairro novo paraíso, Anápolis-GO.

Aquino, R. N. D. A. (2011). Utilização de espécies vegetais na recuperação de solo sob área degradada Manaus-AM.

Batista, D. C. L. (2016). Impacto ambiental por ocupação em encostas urbanas: estudo de caso no bairro Gilberto Mestrinho Zona Leste de Manaus.

Benchimol, S(2009). Amazônia Formação Social e Cultural. Editora Valer, Manaus.

Brancalion, P. H. S., Rodrigues, R. R., Gandolfi, S., Kageyama, P. Y., Nave, A. G., Gandara, F. B., ... \& Tabarelli, M. (2010). Instrumentos legais podem contribuir para a restauração de florestas tropicais biodiversas. Revista Árvore, 34, 455-470.

Derisio, J. C. (2016). Introdução ao controle de poluição ambiental. Oficina de textos.

da Silva, M. L., \& Andrade, M. C. K. (2017). Os impactos ambientais da atividade mineradora. Meio Ambiente e Sustentabilidade, 11(6).

de Souza, D. O., do Nascimento, M. G., \& dos Santos Alvalá, R. C. (2015). Influência do crescimento urbano sobre o microclima de Manaus e Belém: Um estudo observacional. Revista Brasileira de Geografia Física, 8(04), 1109-1124.

de Souza, M. G., \& da Cunha Albuquerque, A. R. (2020). Índice de vegetação diferença normalizada (ndvi) no estudo da arborização urbana de ManausAM/Brasil. XVI Fórum Ambiental.

Durigan, G., \& Engel, V. L. (2012). Restauração de ecossistemas no Brasil: onde estamos e para onde podemos ir. Restauração ecológica de ecossistemas degradados. Editora UFV, Viçosa, 1-23. 
Research, Society and Development, v. 10, n. 16, e290101623764, 2021

(CC BY 4.0) | ISSN 2525-3409 | DOI: http://dx.doi.org/10.33448/rsd-v10i16.23764

Farias, E. (2015). Não adianta culpar o Pará, fumaça em Manaus veio das queimadas no Amazonas. http://queimadas.cptec.inpe.br/ rqueimadas/material3os/2015_Farias_Fu macaManausQueimadas_AmazoniaReal_DE3os.pdf

Giangiulio, A. R. (2009). Gestão ambiental aplicada a prevenção, controle e recuperação de erosão linear acelerada no município de Ipeúna-SP.

Gil, A. C. (2008). Métodos e técnicas de pesquisa social. (6. ed.) Ediitora Atlas SA.

IBGE. (2019). Instituto Brasileiro De Geografia E Estatística. https://www.ibge.gov.br/geociencias/organizacao-do-territorio/tipologias-do-territorio/15788aglomerados-subnormais.html?=\&t=o-que-e

IPEA. (2019). Instituto de Pesquisa Econômica Aplicada. https://www.ipea.gov.br/portal/

Limeira, C. M. C. D. R. (2017). Percepção da qualidade de vida dos moradores da Ilha Mem de Sá, Itaporanga D'Ajuda/SE.

de Macena, L. S. S., \& Costa, R. C. (2012). A cidade como espaço do risco: estudo em bacias hidrográficas de Manaus, Amazonas-BR. Revista Geonorte, 3(4), 318-330.

Maciel, F. B. (2016). Assentamentos precários: o caso de Manaus.

Magalhães, R. C., Molinari, D. C., \& Gomes, R. C. M. (2011). Produção Do Espaço E Alterações Das Características Fitogeograficas E Geomorfologicas Em Manaus: $O$ Caso Do Tarumã E Distrito Industrial 2 (AMAZONAS). Revista Geonorte, 2(3), 40-58.

MapBiomas (2021). Mapeamento anual das áreas urbanizadas no Brasil entre $1985 \quad$ a 2020. https://drive.google.com/file/d/1RT7J2jS6LKyISM49ctfRO31 ynJZXX_TY/view?usp=sharing

Ministério Do Meio Ambiente - MMA (2013). Sustentabilidade - https://www.gov.br/mma/pt-br/assuntos/agendaambientalurbana

Nogara, T., \& Wobeto, V. (2019). Implicações da Crise Migratória Venezuelana para as Políticas Brasileiras de Segurança e Defesa: Perspectivas para o Equacionamento de Conflitos / Implications of the Venezuelan Migration Crisis for the Brazilian Security and Defense Policy: Perspectives for Conflict Management. Espaço Aberto, 9(1), 23-42. doi:https://doi.org/10.36403/espacoaberto.2019.19021

Oliveira, F. M., Araújo, R. L., Carvalho, J. S., \& Costa, S. S. (2008). Determinação da variaçâo no microclima de Manaus-AM por atividades antropogênicas e modulações climáticas naturais. Acta Amazônica, 38(4), 687-699.

Oliveira, J. P. C. de ., Correia, D. B. ., Verçosa, C. J. ., Figueroa, M. E. V. ., Cabral, C. da P. ., Vitor, L. N. A. ., Santos, A. F. dos ., Martins, A. S., Teixeira, L. M. ., Pereira, G. G. ., Anunciação, J. A. O. da ., Pereira, F. D. ., Vasconcelos, J. M. P. B. L. de ., Silva, A. S. O. da ., Fernandes, N. de S. ., Oliveira, P. S. de ., Sampaio, N. K. S. ., Santos, R. H. L. dos ., Barros, J. E. L. de, \& Santos, M. A. F. dos . (2021). A utilização inadequada do solo e seus impactos na degradação das áreas . Research, Society and Development, 10(12), e35101219948. https://doi.org/10.33448/rsd-v10i12.19948

Oliveira, W. (2020). A Imigração Dos Venezuelanos Para O Brasil E A Atuação Da Polícia Federal Na Fronteira: uma análise sobre as solicitações de refúgio e residência temporária. Revista Brasileira De CiêNcias Policiais, 11(3), 231-263. doi:10.31412/rbcp.v11i3.657

Pereira, A. S., Shitsuka, D. M., Parreira, F. J., \& Shitsuka, R. (2018). Metodologia da pesquisa científica. [e-book]. Santa Maria. Ed (pp. 3-9). UAB/NTE/UFSM. https://repositorio. ufsm. br/bitstream/handle/1/15824/Lic_Computacao_Metodologia-Pesquisa-Cientifica. pdf.

Rodrigues, B. S. (2020). Em defesa do Eldorado: disputa internacional pela Amazônia brasileira.

Simon, M. S. (2014). As "matas imensas, glória e coroa de todos os bosques do mundo" e a "zona-da-mata": sociedades, paisagens e recursos florestais na colonização do Nordeste (CA 1780-1808) (Master's thesis, Universidade Federal de Pernambuco).

SEMA. (2021). Secretaria de Estado Do Meio Ambiente. http://meioambiente.am.gov.br/downloads/ 